\title{
Charting the Emerging Financial Services Ecosystem of Fintechs and Banks: Six Types of Data-Driven Business Models in the Fintech Sector
}

\author{
Julian Schmidt \\ University of Hamburg \\ 2schmidt@informatik.uni- \\ hamburg.de
}

\author{
Paul Drews \\ Leuphana University of \\ Lüneburg \\ paul.drews@leuphana.de
}

\author{
Ingrid Schirmer \\ University of Hamburg \\ schirmer@informatik.uni- \\ hamburg.de
}

\begin{abstract}
The competition and the collaboration of established banks and challenging fintechs are expected to dramatically change the financial services ecosystem. The different types and roles of fintechs as new niche players in the ecosystem are not well understood so far. However, a better understanding of these types and roles is required for incumbent as well as for new actors for defining and aligning their strategies. In this paper, we analyze the business models of 195 fintech companies with a special focus on the role of data. Based on this analysis, we present a structured overview of fintechs' business areas as well as six data-related business model types. This paper contributes to the research on data-driven business models and business ecosystems by applying and modifying an existing approach for classifying new niche players based on the data dimension of their business models.
\end{abstract}

\section{Introduction}

During the last decades, companies from the financial services sector became more and more digital in its processes, products and communication. Due to this development, cooperation increased as companies and banks in particular cannot only rely on their internal competencies. Instead, they have to complement their own competencies with those of other companies of the financial services sector [1], [2]. Furthermore, the emergence of new niche market players, called fintechs, which entered the financial services market, lead to further changes in the ecosystem [3].

The term fintech is used for companies in the financial service sector which create, change or improve existing services, products, processes or business models based on new technological opportunities with the aim to increase the quality for the customer who is more and more digitally connected [4]. The digital business strategy, resources and capabilities of banks have to be tightly integrated and improved to keep up with the challenges of digitalization [5]. Banks and fintechs now form a new business ecosystem, in which "companies co-evolve capabilities around a new innovation" [6].

The collaboration of banks and fintech companies is seen as a key factor for the success of digitalization endeavors in the future [2], [7]. The weaknesses of banks and the strengths of fintech companies are expected to provide good opportunities for cooperation. Hence, a better understanding of the business ecosystem could support strategy development and implementation for both parties.

A comprehensive overview and classification of fintechs is still missing. Existing literature characterizes the fintech industry as a living body with a very flexible and changing nature [4]. In this industry, multifaceted interdependencies create numerous connections that are affected by multiple stakeholders [1]. Our analysis focusses on fintechs as new niche players in this ecosystem as this is the area in which major changes take place.

For analyzing and classifying the fintechs, we employed an analysis based on the business models with a special focus on the role data. Data is expected to play an increasingly important role for business models in several industries as new technologies can be used for developing new ways of gathering, analyzing and commercializing data [10]. The quote "data is the new oil" [11] became widespread and established the analogy of data as a natural resource that needs to be exploited for growth and profit [10]. In some industries, such as the banking industry, data has spurred entirely new business models [10]. For the business models of fintechs, data is a core matter. Therefore, data should be considered as a relevant dimension for creating and maintaining an overview of the actors in the financial services ecosystem.

Hence, our paper addresses the following research question: Which different types of fintech business models exist in the financial services ecosystem and what is the role of data for these companies? 


\section{Related Research}

Business ecosystems research is a growing research area driven by the need for a new paradigm for strategizing, competing and innovating in the networked economy [12]. Moore explains business ecosystems as an allegory of natural ecosystems in order to present the way companies should do business together [6]. Business ecosystems can be defined as a set of actors, who contribute to the core purpose of the business ecosystem by producing value for its customers through innovation. Pierce explains business ecosystems as networks of organizations that are held together through formal contracting and mutual dependency [13]. The entities of a business ecosystem are structured around core firms, whose centrality is established on the basis of control [14]. In general, the business ecosystem view includes, in contrast to the conventional value chain view, not only the value chain of a single enterprise, but also large networks of actors (i.e., distributors and customers) [6], [15], [16]. The use of a business ecosystem analogy has the value of being able to account for the change dynamics, and the strategic implications of those changes, for organizations; key aspects of business ecosystems are their members and their roles, their coevolution, the dynamics of change, and company strategies for business ecosystems [15], [17].

Despite this current focus of research, business ecosystems are neither understood nor managed well enough [16]. In particular, new research challenges arise as a result of the increasing complexity of business ecosystems and the platform-driven society [18]. However, the existing business ecosystems have limited scope, various degree of transparency, insufficient support for search and evaluation of useful quality artifacts, and none does fully support a wide range of shared artifacts from a wide range of actors [19]. There is a need for creating a common understanding of the roles of partners and aligning motivations for participating in a business ecosystem [15]. In particular, there must be substantial improvements in traditionally unrelated and partially isolated research areas which are namely enterprise architecture and enterprise modelling and new business models and data [19]. For better analyzing and understanding the role of actors in the focal business ecosystem, we draw upon the widely used concepts of business models. The existing literature on business models and fintechs has evolved during recent years [3], [20] but is still in a nascent status.

In this paper, business models are used as a unit of analysis. This approach has already been applied in research [21], [22] for better understanding the role of actors in the focal business ecosystem. The business model of a company mainly describes external and internal activities around the value proposition, i.e. the value created for users by the offering based on the technology. In the world of fintechs, Osterwalder's practitioner-oriented business model canvas [23] is widely accepted and used [24].

Following our research question and focus, we searched for extensions to business model approaches that emphasize business areas and data as fundamental elements of a business ecosystem beside further elements like government, financial customers and traditional financial institutions [25], [26]. Several authors suggest Data-as-a-service and Analytics-as-aservice as new service types [27]. Data-as-a-service is defined as "New forms of data services that aggregate and provide accesses to a wide range of public and private data by partnering with data providers, aggregators, and clients" [27] offering a "rich set of data processing, management, and access services." Analytics-as-a-service is defined as "Business Intelligence reporting, text analytics, and advanced analytics such as predictive modelling, all made in composable forms to allow for direct consumption, integration and customizations" [27]. In conclusion, the research challenge of combining traditionally unrelated research areas [19] needs to be solved by combining single methods from these research areas in relation to existing business ecosystems to reach a substantial improvement for understanding and managing business ecosystem. Furthermore, from the business ecosystem perspective of financial services the business model and the data perspective are fundamental for understanding and managing this business ecosystem.

\section{Research Design}

In a first step, we created a sample of fintechs offering products or services in Germany for our analysis. The sample of fintechs was created by using and integrating several sources from practice, as there is not one single comprehensive website or portal listing the majority of fintechs. Each of the sources provided a set of ten up to 150 successful or presumably successful fintechs from the last two years offering its services to German banks. Lists we used include: Deutsche Start-ups [28], Investors Marketing [29], Handelsblatt [30], Payment and Banking [31] and Friendsurance [32]. In total, the underlying sample consists of 195 fintechs. In relation to the whole population, the fintech market in Germany contains approximately 350 fintechs [29], [30]. With this kind of random sampling, we achieve a representative sample which allows generalization, so research bias through a selective choice of the sample is avoided. 
In the next step, further publicly available data was gathered for each fintech of our sample, especially regarding their business models [20] and the role of data for their business models [10]. We gathered this information by using secondary data to ensure descriptive validity. The websites of the fintechs were used to gather information about the value proposition as well as internal and external core competencies, pricing models and target group [14].

We searched each of the websites for relevant information about the business models based on the business model canvas by Osterwalder et al. [23] and and the data-driven business model (DDBM) framework by Hartmann et al. [10]. In a further step, the identified data was coded using a detailed excel spreadsheet. Coding is described as "process of attaching labels to a segment or a phrase that summarizes and categorizes this data" [33]. To ensure the reliability of the coding and the comparability to the study of [10], features of the framework were clearly defined prior to coding. Furthermore, the same methods were used. The manual annotation was performed two times. This procedure is necessary because the coders interpretation becomes more and more viable with increasing experience of interpreting the textual data of this special topic [34]. After the coding process, each fintech was double-checked to ensure all criteria of the business model and DDBM are covered.

In the third step, we used a twofold approach for classifying fintechs. We started by clustering the fintechs by business areas based on the information about their business model to gain an overview about the large variety of different and new finance-specific services. This classification of business areas was primarily based on the description of the two building blocks key activities and value proposition. Furthermore, we analyzed the underlying business models regarding the data dimension. This was done by applying the taxonomy of Hartmann et al. [10]. Based on the data generated by applying the taxonomy and by drawing upon the business model types developed by Hartmann et al., we developed six business model types that help to better understand the role of fintechs in the financial services ecosystem.

\section{Key Results: Data-driven Business Models in the Fintech Sector 4.1. Fintechs' Business Areas}

We clustered the fintechs' business models into seventeen business areas (see Table 1). While most fintech business models are focused on one business area, some provide services for more than one. The analysis relies on the core business model of the fintechs, particularly on key activities and value proposition. Therefore, additional services that are not part of the value proposition are not considered in the analysis. Due to the limited space and as we used some well-known business areas, we only cover those which require a description. The business area API banking is used for fintech business models, which offer single products or services containing complete or parts of core banking functionalities as an API (application programming interface). The category banking summarizes fintech business models that offer products or services which extend or improve existing banking functionalities. Order/Cash includes fintechs offering products or services related to shop orders and payments. Further, we found out that most business models of the fintechs in our sample offer products or services for savings, payment, insurance, banking and lending.

\subsection{Data-related Characteristics of Fintechs' Business Models}

In the next step of the analysis, the data perspective was added and combined with the business areas. Therefore, the DDBM framework [4], [10] which based on the business model canvas [23] too, was applied to analyze the general role of data in the business models of fintechs with a strong focus on the core business model as described in business area analysis. The DDBM framework in general consists two parts: a set of attributes to analyze DDBM and a set of specific DDBM types for the start-up sector.

The set of attributes to analyze the business models in regard to data was identified as sufficient for the business ecosystems of financial services and in particular fintechs.

In contrast, the set of specific DDBM types for the start-up sector is not applicable to the business ecosystem of financial services and in particular fintechs. The identified DDBM types of start-ups by Hartmann et al. [10] are mainly differentiated by the dimensions key resources and key activities. For out data set, we had to employ different criteria for developing consistent DDBM types.

First, five of the six identified DDBM types of start-ups of Hartmann et al. include only a single key resource. Fintechs instead, use a combination of several key resources. Most of them use e.g. customer provided data (79 \%) and external acquired (54\%). Further, the focus on free available, customer provided and tracked data is not feasible for DDBM of fintechs, e.g. free available data is only relevant to a very low number of fintechs. The diversity of underlying key resource of fintechs is more diverse, open data is used 
by $10 \%$ of all fintechs and most of the fintechs, which are using internal data sources, track or generate the data $(43 \%)$. Just $16 \%$ use existing internal data sources.

Second, four of six identified DDBM types of startups of Hartmann et al. include a single key activity. Fintechs instead, use a combination of several key activities. Most of them e.g. process data (83\%) and perform descriptive analytics $(57 \%)$. Further, the focus on clusters of key activities like analytics which was conducted by Hartmann et al. instead of differentiation between descriptive, predictive and prescriptive analytics is not feasible for fintechs, too. For example, predictive analytics is conducted by $22 \%$ the fintechs in the sample and prescriptive analytics are barely conducted.

Third, none of the six identified DDBM types of start-ups of Hartmann et al. consider further dimensions. In contrast, the majority of the fintechs offer information $(65 \%)$ and data $(64 \%)$ to its customers. It is also noteworthy that $39 \%$ of the fintechs offer, additionally to the data products or services, non-data products or services, too. Additionally, the target customer of the fintechs is rather diverse. One third of the fintechs focus on business customers, one third on private customers and one third of the fintechs target both. Therefore, both dimensions value proposition and target customer also have to be considered for DDBM types fintechs.

In conclusion, we found out that the DDBM of fintechs represent a specific business ecosystem and not generally comparably to DDBMs of start-ups. For this reason, we developed new DDBM types of fintechs which are described in the following section.

\subsection{Six Types of Data-Driven Business Models within the Fintech Sector}

For our analysis, we started with the types identified by Hartmann et al. in their study on start-up companies with a cross-sectional dataset [10]. Hartmann [10] identified six types of data driven business models: free data collector and aggregator, analytics as a service, data generation and analysis, free data knowledge discovery, data aggregation as a service and multi-source data mash-up and analysis. We tried to match these types with the data-related activities of the fintechs of our sample. The analysis showed that the types identified by Hartmann et al. do not fit to our sample because the types are based on free available data, a strong focus only on customer provided data instead of a combination of customer provided and acquired data. The key activities are too unspecific for fintechs because there are further key activities which are conducted and therefore have to be considered. Hence, the six types of DDBMs derived from start-up companies don't fit well for fintechs. Instead, we developed new DDBM types for the fintech sector by using the taxonomy of Hartmann et al. and by considering the business areas (see 4.1).

4.3.1. Data Processing Model. The first type of business models is called data processing model. Fintechs using this type deliver data as value to their customers. The delivered value is typically a service which is mainly based on external data as input for its key activities. The processed data is offered to individual customers or businesses. The model is primarily used by fintechs from the business areas $\mathrm{P} 2 \mathrm{P}$ and payment.

The canvas in Figure 1 depicts this type. We explain this type by describing an example of the fintech RatePay (ratepay.com) of the business area payment. RatePay offers individual payment solutions for all types of online shops and handles the entire payment process including instalment payment without identification procedure, immediate online approval, open invoice, direct debit and payment in advance. RatePay was bought by Bain Capital Private Equity and is now part of the Concardis' payments platform. The value proposition of this fintech is secure payment solutions for online retail. RatePay tracks the payment data by the customers of the online shop and processes the payment.

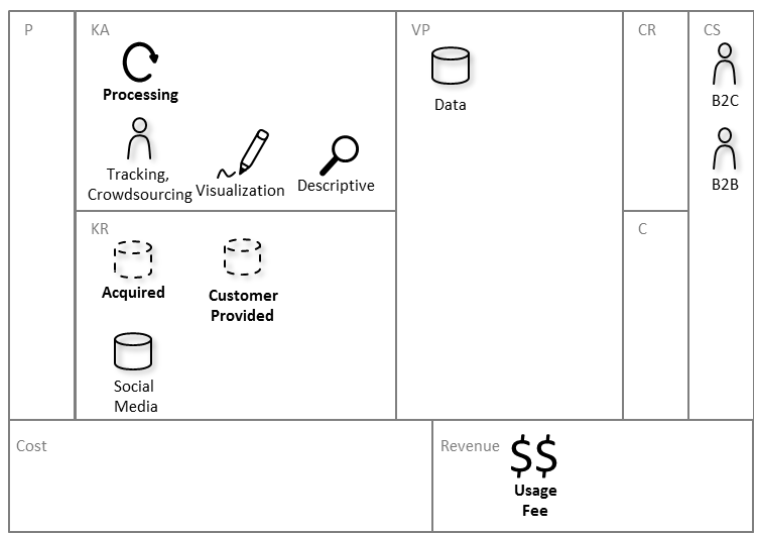

Figure 1. Data Processing Model

Additionally, the data of the target payment providers is acquired. The payment methods are offered to businesses like online shops and also the visualizations and descriptive analytics components are offered to businesses in order to analyze the processed payments. During the payment processing activities, the payment data of the online shops is processed and transferred to a financial service provider. 
Table 1. Results of the DDBM Analysis of 195 Fintechs by Business Area

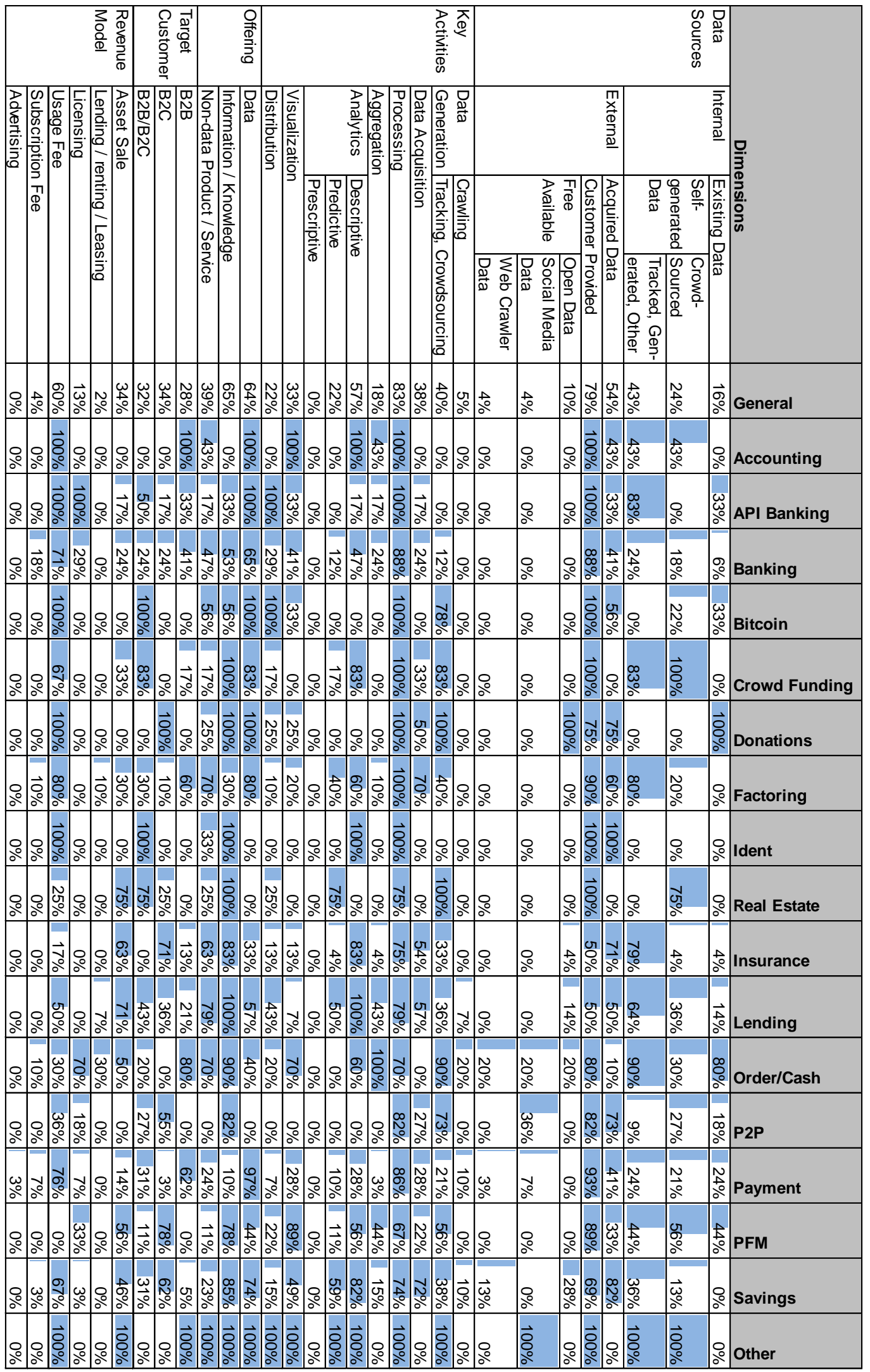


The fintech does not store any payment data but uses the data of the online shop. Although the fintechs' core competence is delivering trustful online payment methods, a further key resource is the interface to the data of the online shops. The RatePay example focusses on businesses, but this type focuses on the individual customer, because in particular P2P payments rely on this group.

Fintechs with fast and convenient data processing as a service offer the opportunity to optimize and innovate business processes and services within the bank. In the example above, the impact is the requirement of the data processing service of the fintech which can be used to integrate services to process data using third party data. The revenues are depending on the usage of the service.

4.3.2. Information Processing Model. The second type is called information processing model. Fintechs using this type deliver value in two steps. In the first step, fintechs establish access to a variety of data sources and in advance customer provided data. Therefore, the fintechs use tracking and data acquisition as key activities. In the second step, the data is processed to customer readable und understandable information. Processing means in this case, that only the important data is chosen and presented to the customer. Further offerings are sometimes non-data activities like a call center unit. The processed information is mainly offered to individual customers but in some cases also to businesses. This type is mostly used by fintechs from the business areas crowdfunding, real estate, factoring and donation.

The canvas in Figure 2 depicts this type. We explain this type by describing an example of the fintech Companisto (companisto.com) of the business area crowd funding. Companisto offers innovative investment opportunities to invest in start-ups. Companisto enables investors to become a shareholder in start-ups and benefit from value increases and profits. The offering is delivered to individual customers and businesses. The data of investment projects is acquired or crowdsourced. Companisto processes the data and creates investment projects, so that investors can invest into a company or a start-up by receiving a share in the company's profits or fixed interest payments. The company conducts internal and manual descriptive analytics in order to determine the risk of an investment project. Although the fintechs' core competence is to bring information for investment projects into to investment market place, further key resources for Companisto is the risk profile data which is created during each crowdfunding investment project.

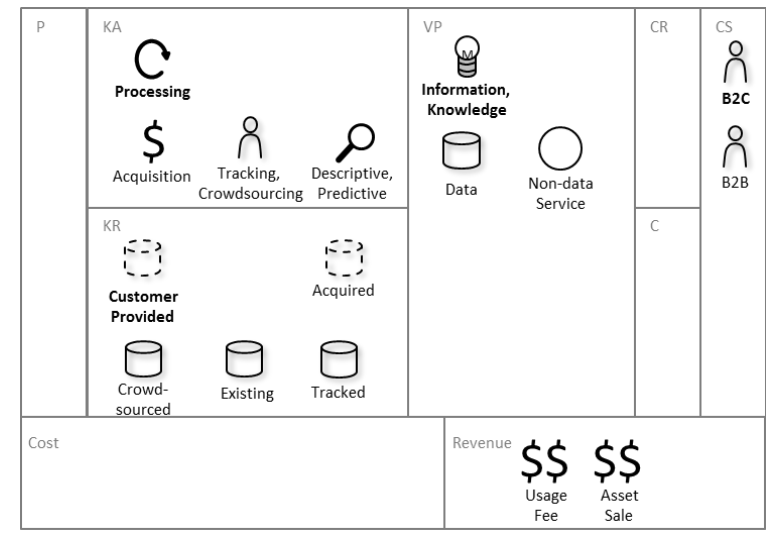

Figure 2. Information Processing Model

Using the business model canvas to explore the potentials of information processing fintechs offers the opportunity to focus on new forms information processing with low entry barriers. In the example above, the impact is the requirement of the key activity processing of data from a number of sources and the transformation of the data into information.

However, this type (information processing model) can be used by banks to innovate and optimize the information processing within the bank or as a cooperation partner. The revenues are depending on the usage and the number of sales.

4.3.3. Data Aggregation Model. The third type is called data aggregation model. Fintechs using this type deliver value as aggregated data to its customers. The delivered value is typically an aggregated set of data accompanied by a number of visualization and analytic tools.

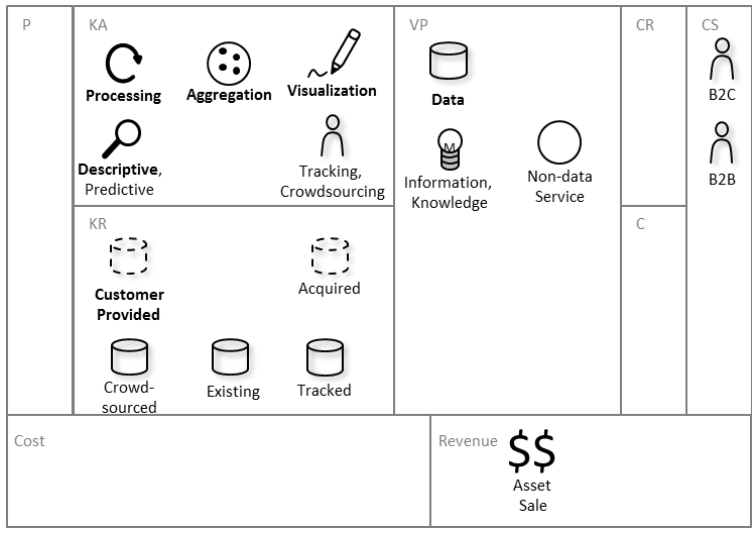

Figure 3. Data Aggregation Model

The data sources are the same as in the information processing model. The aggregated data is offered to individual customers or businesses. This type is mostly 
used by fintechs from the business areas accounting, personal finance management and order/cash.

The canvas in Figure 3 depicts this type. We explain this type by describing an example of the fintech feelix (myfeelix.de) of the business area personal finance management. Feelix offers access to a digital finance planning tool with automated contract checks and an integrated expert panel to its customers. The canvas shows that the fintech's key value proposition is transparency in financial and insurance questions, thus helping to save time and money and to get access to additional data assets. This product is delivered to the individual customer. Although the fintechs' core competence is delivering access to automated financial advices, especially the customer provided data including the contracts to banks and insurances are basis for all these activities.

The business model canvas shows that data aggregation fintechs offer the opportunity for banks to integrate such services into their own service portfolio, e.g. in order to support multi-banking capabilities, or as a part of an independent financial advisor. In the feelix example, the business model imposes a pressure on banks to open their processes and IT for a cooperative community of fintechs and banks. The revenues in the model are depending on the number of sales of the service.

4.3.4. Data Analytics Model. The fourth type is called data analytics model. Fintechs using this type deliver value by processing and analyzing acquired or customer provided data. The delivered value is typically not a data set, but recommendations how the customer should behave in his or her individual financial situation. This type is mostly within the business areas savings, insurance and identification.

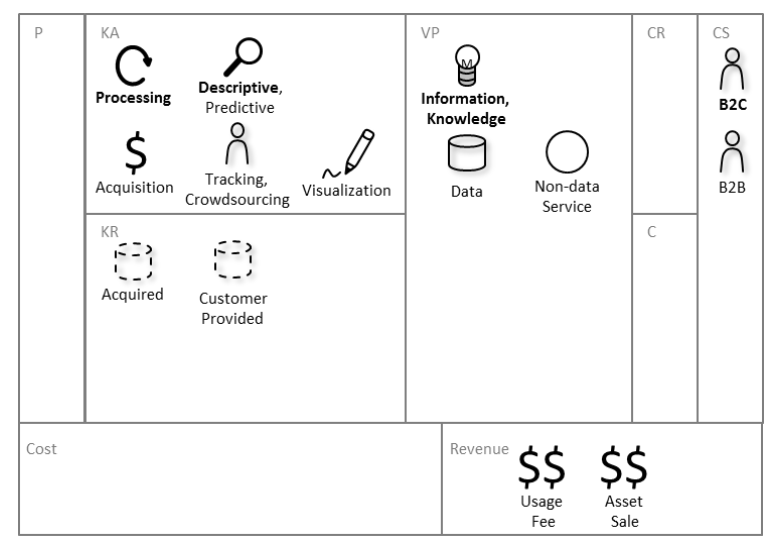

Figure 4. Data Analytics Model

This type is mostly used by fintechs from the business areas savings, insurance and identification.
The canvas in Figure 4 depicts this type. We explain this type by describing an example of the fintech LIQID (liqid.de) of the business area savings. LIQID offers access to investment strategies, instruments and conditions to its customers. In the past, such insights were only accessible for high-net-worth customers. In the example, the fintechs key value proposition is to create and process individual investment portfolios. LIQID analyzes the existing investment strategy and accesses acquired financial data from the investment market. Finally, the fintech processes the investments. According to market changes the investment portfolio data is retrieved, analyzed and optimized.

Data analytics fintechs offer the opportunity to establish state of the art analytic processes by using external services of fintechs or as cooperation. The revenues of this model are depending on the usage and the number of sales of the service.

4.3.5. Data Distribution Model. The fifth type is called data distribution model. Fintechs using this type deliver value by processing and distributing mainly customer provided and acquired data. The delivered value is typically a set of data or a set of information. In contrast to the data and information processing model, fintechs focusing on the data distribution model process and distribute data as a key activity.

The delivered value is typically not a data set, but recommendation how the customer should behave within the individual financial situation. This type is mostly used by fintechs from the business areas cryptocurrency, API banking and banking.

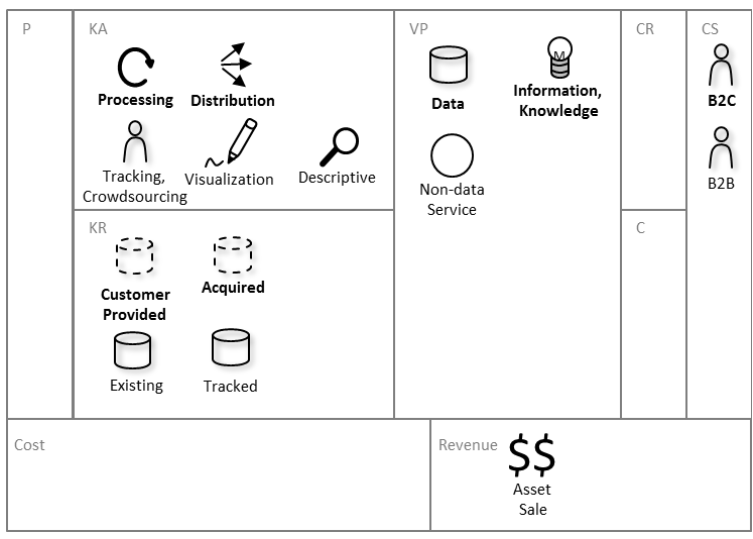

Figure 5. Data Distribution Model

The canvas in Figure 5 depicts this type. We explain this type by describing the example of the fintech figo (figo.io) of the business area API banking. Figo offers a banking service which bridges the gap between new and innovative financial services and 3,100 sources of finance with over 55 million users. In the canvas, the 
fintechs' key value propositions are the banking programming interface and a number of connected sources of finance. This product is delivered to businesses. During the production process, the connected financial data is processed and aggregated. The data is stored aggregated in a database as a key resource.

Although the fintechs' core competence is to deliver a transparent and state of the art programming interface, a further key resource is the amount of financial data which is stored in the fintech's database. The figo example focusses on businesses but this type also contains transitive connections to the individual customer because connected banks or fintechs deliver its own value to this customer group.

Fintechs with state of the art technology and interfaces to financial data offer the opportunity to extend a company's data capabilities by using a network of cooperative data use. In the figo example, the impact on the relation between banks and fintechs is the need of improving the key activity data distribution to enable and establish "multi-banking" or "multi-finteching" capabilities. The revenues are depending on the number of sales of the service.

4.3.6. Data Value Chain Model. The sixth type is called data value chain model. Fintechs using this type deliver value along the complete data value chain [51]. In the first step, the fintech acquires and tracks data. This data is aggregated, processed and analyzed in the second step. In the third step, the results are distributed as data and information mainly to the individual customer. This type is mostly used by fintechs from the business area lending.

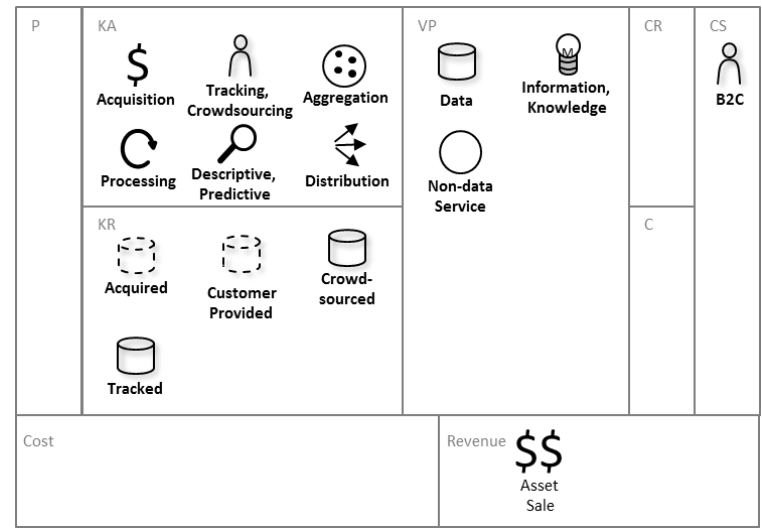

Figure 6. Data Value Chain Model

The canvas in Figure 6 depicts this type. We explain this type by drawing upon the example of the fintech auxmoney (auxmoney.com) from the business area lending. Auxmoney offers an online credit market place to its customers where private investors can invest directly in selected credit projects. In the canvas, the fintechs key value propositions are the elimination of the high costs of traditional banks, significantly better credit ratings for credit seekers and higher returns for investors.

The product is delivered to individual customers and businesses. During the transfer of these so-called peer-to-peer loans, the valuation criteria for lending are different from those of banks. For this reason, selfemployed persons or freelancers who are often rejected by banks have the chance of receiving a loan. Creditors of auxmoney have the possibility to tailor a customized loan-based on a risk profile. Although the fintechs' core competence is an online credit market place, further key resource is the risk profile data which is created during each lending project. Fintechs in this model have the opportunity to focus on completely independent business models. Banks have to decide how to deal with such kind of business models cooperation or competition. The revenues are depending on the number of sales of the service.

\section{Discussion}

The capabilities of explaining how multi-sided business evolve and how such ecosystems can be managed or even orchestrated is a current research challenge [16], [18]. Our exploration of the fintech ecosystem in regard to business areas and data is based on the assumption that detailed information about each player within a business ecosystem on different architectural levels is available.

First, one of the current research challenges in business ecosystem research is to gain a better understanding on business ecosystems [16]. In particular the need of correlating business ecosystem research and business model research is fundamental [1]. Therefore, wrong assumptions lead to a misunderstanding of the ecosystem and this finally lead to wrong strategies for actors in the business ecosystem. Our analysis of the business model regarding business areas and data, as two important elements of the business ecosystem of fintechs [25], [26], combines both mentioned research areas. In case of a business ecosystem view the business areas of fintechs have to be extended to the seventeen identified business areas and should not be limited to single ones. Even though the business areas savings and payment represent almost one third of the fintechs in our dataset, not only fintechs within the business areas but also the other fifteen business areas have to be considered. This perspective, which based on qualitative research of 195 business models of fintechs, focusses on limited scope, various degree of transparency and insufficient support of business 
ecosystems. Further, it supports to understand the industry structure this ecosystem [1], [17].

Fintechs as one group of actors in the financial service ecosystem are in general similar to start-up companies regarding the role of data [10]. But in detail, new types of DDBMs are necessary to describe the DDBMs of fintechs. In particular, the focus on a single key activity and key resource which have been used for start-up companies is not enough to differentiate between DDBMs of fintechs. The analysis regarding data based on the DDBM framework of Hartmann et al. as initially based on data specific to the core datarelated characteristics. This leads to patterns of common data-oriented divisions that have similar datarelated characteristics and emphasizes the complexity of the data sources and evaluations, and thus completely distracts itself from Hartmann et al. For this reason, six new types of business models are the result of our study. These six types of DDBMs are differentiated by its key resources, key activities and its value proposition as well as additionally customer segments and revenue streams. In detail, our data shows that customers of fintechs almost equally distributed among B2B, B2C and B2B/B2C. One other key finding is that social media data or web crawler data is barely used by fintechs. The key activities web crawling and descriptive analytics are also barely used. As a further key finding only asset sale and usage fee are used as revenue stream. On this basis, we have investigated subject-specific data-relevant DDBM types and see this characterization effective for DDBM type formation for fintechs.

Finally, the DDBM analysis and the newly developed types of DDBM lead to more insight to understand and to manage the financial service ecosystem with a focus on fintech, which is one of the key weaknesses of banks in mastering the digital transformation [16].

Our results are also relevant for practice as they support actors and stakeholders of the ecosystem in better understanding and managing the business ecosystem. In practice, banks could use the results to evaluate future cooperation and increase the influence in the financial services ecosystem.

However, two types of limitation apply to the study: There are constraints regarding (1) the sample size, as well as (2) the geographical focus of the sample. Furthermore, the paper focused on fintechs, which were marked as successful in current times or potentially successful in the future. Most of the analyzed fintechs have not been established five years ago. Another aspect is the geographical limitation of the analyzed fintechs, because all of them offer at least one product or service to German customers.

\section{Conclusion and Outlook}

This paper makes several contributions. We contribute to the currently scarce empirical body of business ecosystems and in particular the financial services ecosystem by identifying six data-driven business model types of fintechs, by describing the role of data in their business models and by relating them to business areas. The paper provides an empirical analysis of data-driven business models (DDBMs) in the financial service ecosystem and extends existing research of Wörner et al. [8], Hartmann et al. [10] and de Reuver et al. [18] by describing a research approach, which supports the analysis of business models in a business ecosystem with a focus on the role of data. The six newly identified types of DDBMs in the financial services ecosystem extend the existing types of DDBMs which have been derived from the cross-industry start-up ecosystem [10]. Therefore, the financial services ecosystem and especially the types of emerging fintechs become more transparent. These types and their link to the seventeen business areas provide the opportunity to gain a better understanding of a specific business ecosystem.

Furthermore, we suggested a new way of visualizing data-related characteristics of business models based on the business model canvas [23]. The visualizations support gaining a better understanding of the business ecosystem [1]. The presented visualization can be used for analyzing new fintechs entering the financial services ecosystem. Additionally, they can be used for visualizing the data-related characteristics of business models in other domains as well. For future research, we see several ways to further increase the understanding of the financial services ecosystem. We consider the following research questions to be relevant for upcoming studies: (1) What differences or similarities can be identified by extending the sample with a more international set of fintechs? (2) How do current cooperation models and archetypes within the financial services ecosystems with regard to banks and fintechs look like?

\section{References}

[1] B. R. Iyer and R. C. Basole, "Visualization to understand ecosystems," Communications of the ACM, vol. 59, no. 11, pp. 27-30, 2016.

[2] E. Graupner, F. Melcher, D. Demers, and A. Maedche, "Customers' Intention to Use Digital Services in Retail Banking - An Information Processing Perspective," ECIS Completed Research Paper, Paper 61, 2015.

[3] A. Mackenzie, "THE FINTECH REVOLUTION," London Business School Review, vol. 26, pp. 50-53, 2015. 
[4] L. Zavolokina, M. Dolata, and G. Schwabe, "FinTechWhat's in a Name?," ICIS Completed Research Paper, 2016.

[5] Y. Chan and S. Ahuja, "Digital Ecodynamics in Small Firms: Using Information Technology to Compete," ICIS Completed Research Paper, 2015.

[6] F. Moore, "Predators and Prey: A New Ecology of Competition," Harvard Business Review, vol. 71, pp. 75-86, 1993.

[7] Santander InnoVentures, "The Fintech 2.0 Paper: rebooting financial services," Available at: http://www.oliverwyman.com/content/dam/oliver-wyman-/global/en/2015/jun/The-_Fintech_2_0_Paper_Final_-PV.pdf (Accessed: 30 April 2016), 2015.

[8] D. Wörner, T. Von Bomhard, Y.-P. Schreier, and D. Bilgeri, "The Bitcoin Ecosystem: Disruption Beyond Financial Services?,” ECIS Research Paper, Paper 33, 2016.

[9] P. Haas, I. Blohm, C. Peters, and J. M. Leimeister, "Modularization of Crowdfunding Services-Designing Disruptive Innovations in the Banking Industry," ICIS Completed Research Paper, 2015.

[10] P. M. Hartmann, M. Zaki, N. Feldmann, and A. Neely, "Capturing value from big data - a taxonomy of data-driven business models used by start-up firms," International Journal of Operations \& Production Management, Vol. 36 Issue: 10, pp.1382-1406, 2014.

[11] P. Rotella, "Is Data The New Oil?" Forbes, Available at: http://www.forbes.com/-sites/perryrotella/2012/04/02/is-datathe-new-oil/ (Accessed: 14 November 2016), 2012.

[12] M. Iansiti and R. Levien, "The Keystone Advantage: What the New Dynamics of Business Ecosystems Mean for Strategy, Innovation, and Sustainability," Boston: Harvard Business School Press, 2004.

[13] L. Pierce, "Big losses in ecosystem niches: how core firm decisions drive complementary product shakeouts," Strategic Management Journal, vol. 30, pp. 323-347, 2009.

[14] D. J. Teece, "Explicating dynamic capabilities: the nature and microfoundations of (sustainable) enterprise performance," Strategic Management Journal, vol. 28, no. 13, pp. 1319-1350, 2007.

[15] E. Annanperä, K. Liukkunen, and J. Markkula, "Managing Emerging Business Ecosystems-A Knowledge Management Viewpoint," AMCIS Full Paper, 2016.

[16] M. F. Baghbadorani and A. Harandi, "A conceptual model for business ecosystem and implications for future research," International Proceedings of Economics Development \& Research, vol. 52, pp. 82-86, 2012.

[17] S. J. Mäkinen and O. Dedehayir, "Business ecosystem evolution and strategic considerations: A literature review," pp. 1-10, 2012.

[18] M. de Reuver, C. Sorensen, and R. C. Basole, "The digital platform: a research agenda," Journal of

Information Technology, pp. 1-12, 2017.

[19] J. Krogstie, "Modeling of Digital Ecosystems: Challenges and Opportunities," Collaborative Networks in the Internet of Services, vol. 380, Springer Berlin Heidelberg, pp. 137-145, 2012.

[20] C. Zott, R. Amit, and L. Massa, "The Business Model: Recent Developments and Future Research," vol. 37, no. 4, pp. 1019-1042, 2011.
[21] O. Gassmann, K. Frankenberger, and R. Sauer, Exploring the Field of Business Model Innovation. Cham: Springer International Publishing, 2016.

[22] T. Clauss, "Measuring business model innovation: conceptualization, scale development, and proof of performance: Measuring business model innovation," R\&D Management, vol. 47, no. 3, pp. 385-403, 2017.

[23] A. Osterwalder, Y. Pigneur, and T. Clark, "Business model generation: a handbook for visionaries, game changers, and challengers." Wiley, 2010.

[24] S. Stuckenberg, E. Fielt, and L. Loser, "The Impact Of Software-As-A-Service On Business Models Of Leading Software Vendors: Experiences From Three Exploratory Case Studie," PACIS Proceedings, Paper 184, 2011.

[25] D. W. Arner, J. N. Barberis, and R. P. Buckley, "Fintech, regtech and the reconceptualization of financial regulation," no. 2016/035, 2016.

[26] D. A. Zetzsche, R. P. Buckley, D. W. Arner, and J. N. Barberis, "From Fintech to Techfin the Regulatory Challenges of Data-Driven Finance," European Banking Institute Working Paper Series, 2017.

[27] Y. Chen, J. Kreulen, M. Campbell, and C. Abrams, "Analytics Ecosystem Transformation: A Force for Business Model Innovation," Annual SRII Global Conference, pp. 1120, 2011.

[28] A. Hüsing, "25 frische FinTech-Start-ups, die sich jeder merken sollte." Deutsche Startups, Available at: http://www.deutsche-startups.de/2016/01/29/25-frische-

fintech-startups/ (Accessed: 8 December 2016), 2016.

[29] Investors Marketing, "IM-FinTech-Studie - Marktpotenziale in 2020." Available at: http://www.in-vestorsmarketing.de/data/investors_marketing/media/doc-/IM-FinTech-Studie_2015.pdf (Accessed: 6 June 2016), 2015.

[30] H. Kalafat, "Das sind die zehn größten Fintech-Firmen," Handelsblatt, Available at: http://www.handelsblatt.com/finanzen/anlagestrategie/trends/fintechranking-das-sind-die-zehn-groessten-fintech-firmen/12724676.html (Accessed: 5 July 2016), 2016.

[31] A. M. Bajorat, "German FinTech Overview," Payment and Banking, Available at: http://paymentandbanking.com/german-fintech-overview-unbundling-banks/ (Accessed: 5 July 2016), 2016.

[32] K. Nauck, "Infografik: Die deutsche FintechLandschaft." Friendsurance/Blog, Available at: https://www.friendsurance.de/blog/fintech-deutschland-infografik/ (Accessed: 5 July 2016), 2016.

[33] S. D. Lapan, M. T. Quartaroli, and F. J. Riemer, Eds., Qualitative research: an introduction to methods and designs, Jossey-Bass, 2012.

[34] F. Fastoso and J. Whitelock, "Regionalization vs. globalization in advertising research: insights from five decades of academic study," Journal of International Management, vol. 16, no. 1, pp. 32-42, 2010. 